

\begin{abstract}
In this paper, we investigate the evolving relationship that is occurring in the wake of a prolonged period of funding cuts, between government and voluntary organizations in Ontario. Interviews with government officials delineate a process of formal and informal coercive isomorphism to bring about desired behaviours in voluntary organizations.
\end{abstract}

\title{
Setting the Context
}

During the first three decades following World War II, the federal and provincial governments in Canada were partners in the construction of an elaborate social welfare system that extended educational, health, social, cultural and recreational services to the public (Johnson, 1987). The system was characterized by a complementary relationship between government and nonprofit organizations in the delivery of services. Indeed, this period witnessed an exponential growth in the number of voluntary organizations, as governments provided generous grants to organizations to serve society (Tucker, Singh \& Meinhard, 1990).

The erosion of the social welfare state began, imperceptibly, in the mid 1970s. By 1984, with the election of a Conservative government, the prevailing Keynesian economics was abandoned, to be replaced by a market economy (Rice \& Prince, 2000; Smardon, 1991; Tester, 1996). Social programs were cut, and programs of privatisation and fiscal restraint were pursued. With diminished federal funding, provinces have downloaded responsibilities and cut social spending, expecting the voluntary sector and community networks to fill the vacuum, without increasing their grants.

Several researchers have attested to the state of crisis felt by voluntary organizations as a result of these drastic cuts. Paid positions were lost and recruitment and training had to be curtailed. Forced commercialization, introduction of fees for service, increased accountability requirements, adoption of business practices, and marketing and fundraising strategies, led in many cases, to mission displacement. A sense of vulnerability reduced the role of advocacy and networking for policy changes. Competition increased as the commercialisation of public welfare services forced nonprofit service providers to compete with for-profit service providers for government contracts (Meinhard \& Foster, 2003; Rice \& Prince, 2000; Richmond \& Shields, 2003; Scott, 1992).

The election of a Conservative government in Ontario, on a platform of reducing deficits by making government more efficient and business-like, exacerbated the situation (Ontario Public Service Restructuring Secretariat, Cabinet Office, 1999). Per capita social spending dropped by 20\% over a five year period from 1992-1997 (Ontario Public Accounts, 1989 - 2000). Clearly, realignment was taking place between government and the voluntary sector in Ontario. These changes had an impact not only on the voluntary sector, but also on the relationship between Government and the voluntary sector. In order to discover the nature of this newly evolving relationship and the direction in which the Ontario government was moving, we interviewed 17 civil servants from five ministries that have substantial dealings with voluntary organizations. These interviews revealed a fascinating process of institutional isomorphism. 


\section{Institutional Isomorphism}

Amos Hawley (1968), noting diversity of organizational form across different environments, yet homogeneity of organizational form within the same environment, was the first to discuss the phenomenon of organizational isomorphism. Based on Hawley's observations, Dimaggio and Powell (1983:149) defined isomorphism as "a constraining process that forces one unit in a population to resemble other units that face the same set of environmental conditions." Since Hawley's groundbreaking work, delineation of the concept has followed two distinct paths: organizational homogeneity (i.e. isomorphism) that results from competitive pressures generated by environmental selection processes, as articulated in Population Ecology Theory (Hannan \& Freeman, 1977); and organizational homogeneity that results from normative, mimetic or coercive pressures to gain legitimacy from the institutional environment, as articulated in the New Institutional Theory (Dimaggio \& Powell, 1983; Meyer \& Rowan, 1977).

Meyer and Rowan (1977) were first to point out that not all organizational actions are driven by the quest for efficiency. Organizations may adopt practices that are, in fact, less efficient, but that will defer legitimacy on the organization by important actors in the environment. Dimaggio and Powell (1983) delineated the process of institutionalization by identifying three different ways in which institutional isomorphism is achieved: through coercion, when formal and informal pressures are exerted by powerful institutional players; through mimetic processes, when an organization models itself on other successful organizations, especially in conditions of environmental uncertainty; and through normative pressures, usually applied by professional bodies, to adopt and maintain certain practices. According to Dimaggio and Powell (1983), these are analytically distinct mechanisms, but empirically very hard to separate. Indeed, Mizruchi and Fein (1999) demonstrate how attributing similarity in a population of organizations to one type of isomorphism, for example, mimetic isomorphism, could just as easily be explained by either or both, normative or coercive isomorphism.

Generally speaking, most research cites evidence for institutional isomorphism by measuring outcomes. They attribute the widespread adoption of different forms or practices to institutional isomorphism without actually measuring the process that leads to the isomorphism (Mizruchi \& Fein, 1999). In other words, the forces of isomorphism are inferred by the results. The present paper addresses this weakness by focusing on the institutional players and how they use coercive and normative pressures to bring about change and ensure compliance. There have been but few studies that actually investigated the processes leading to isomorphism. For example, Siegel and Rigsby (1998) investigated the institutionalization process of certified public accountants from a historical perspective; Fusareli (2002) described the effort of policy makers to introduce new testing standards and the impact it had on the local educational system; and Covaleski and Dirstein (1988) examined the processes of institutionalization as expressed through a university's budget planning. Although the first two papers describe a general process of institutionalization, they do not directly examine the means by which both formal and informal coercive and normative pressures are applied. Covaleski and Dirstein (1988:562) on the other hand, describe in detail "how, by whom and for what purposes societal expectations of acceptable budgetary practices are articulated, enforced and modified..." The present paper concentrates its focus on how policy is articulated and conveyed to voluntary organizations. Two policy areas are examined: increased accountability and the desirability of partnerships. The various themes that emerged from interviews with institutional players provide new insight into the process of institutionalization. 


\section{Method}

\section{Sample}

The sample consists of respondents from five Government of Ontario ministries that have substantial dealings with the nonprofit sector. We contacted key administrative officials in each ministry. The objectives of the study were explained to the officials and they were asked to suggest the best way in which to contact those in their ministries who were most closely involved with the nonprofit sector. Each ministry handled our request in different ways, but they were all cooperative. The resulting sample of 17 respondents included deputy ministers, assistant deputy ministers, regional directors, and front-line supervisors ${ }^{1}$.

\section{Interviews}

In-depth, elite interviews were conducted according to guidelines set by Holstein and Gubrium (1995). All but one of the interviews took place in the offices (or boardrooms) of the respondents. Two interviewers were present at each interview. Interviews lasted from an hour to an hour and half and were recorded. One interview, also recorded, was conducted over the telephone. The issues probed in the interviews included: the perception and interpretation of the sociopolitical changes occurring in Canadian society; the general direction in which the voluntary sector is moving; the roles of government, voluntary and for-profit organizations in this new sociopolitical configuration; the interaction of the three sectors in the future; the way in which policy is developed; current and proposed strategies regarding the delivery of social services and the support of cultural and recreational activities.

\section{Analysis}

The interviews were transcribed. The transcribed interviews were content analyzed by two separate raters. The content analysis was carried out at two levels. First, answers to the specific questions asked in the interview were recorded and summarized. At a deeper level, themes that cut across all interviews were identified. Two themes emerged with direct relevance to coercive institutional forces: increased demands for accountability and partnering.

\section{Analysis of Interviews}

Isomorphism, in terms of similar organizational forms, structures and practices, is not measured directly in this paper. Rather, evidence that it exists is based on other surveys of the nonprofit, voluntary sector. Both Meinhard and Foster (2003) and Rice and Prince (2000), in their respective surveys, note several widely adopted trends in the voluntary sector. Among them is an increased emphasis on accountability, and more active pursuit of partnerships with both for-profit and other nonprofit organizations. Our interviews shed light on why these trends are taking place.

\section{Increased Demands for Accountability}

\footnotetext{
${ }^{1}$ We found that the respondents were extremely generous, not only with their time, but with their ideas as well. Assured of the confidential nature of the interviews, they were candid and forthcoming, as willing to point out their weaknesses as they were their strengths. Their dedication to their jobs and their stakeholders is evident in their answers. Taken as a whole, these interviews convey a caring and forward looking civil service in Ontario.
} 
A major shift in government philosophy occurred in Ontario with the 1995 election of the Progressive Conservatives. This government, in power in Ontario for almost 10 years, was initially elected on a platform of reducing deficits by making government more efficient and business-like. With a strong mandate from the electorate, they immediately initiated a new business planning process for all of its ministries.

The business plans were...multi-year commitments on how ministries would achieve their fiscal targets and implement new policy directions and measure performance. Business planning took on a whole new importance and transparency... Ministries were made accountable for producing business plans, for implementing them and for accounting for the results they would achieve through specific performance measures. (Transforming Public Service for the $21^{\text {st }}$ century. Ontario Public Service Restructuring Secretariat, Cabinet Office, 1999: 20).

From our interviews, it is clear that our respondents see this movement towards government efficiency and accountability as a priority not only for their own internal practices, but also as a requirement for their nonprofit clients. There are strong, formal coercive pressures to regulate both financial and professional performance.

We have the responsibility to hold those that we give money to accountable, as we hold ourselves accountable for the money that we have the responsibility to manage. $(001)^{2}$

The public is holding us so much more accountable for how taxpayers' dollars are spent. So as we give those dollars back to organizations, we have to be able to prove that there's a good accounting of how that dollar is spent. (003)

[We have] very specific accountability rules. We have what we call guidelines for transfer payment agreements that we have to follow, so the payment has to be structured in a certain way. There have to be reports back about how the money was used. And there has to be some audit in terms of how the money was used and there is some delegation of authority in terms of I can only sign of up to a certain amount, if it exceeds that than it has to up the ladder and that kind of thing. So it is very clear due diligence rules that are audited by the provincial auditors, so they are very strict. (005)

Accountability requirements are not standardized across all ministries, nor even within certain ministries. Comparing extremes, one respondent provides examples contrasting a highly regulated service with one in which the rules are more informal and implied.

There is quite a prescriptive approach...in our accountability standards. We would be setting out very clearly what we expect of them in terms of complying

\footnotetext{
2 The numbers in the brackets indicate the identification number of the taped interview. In order to maintain full confidentiality, we have removed any names or references in the quotations which could conceivably identify the interviewee.
} 
with whatever the relevant terms and conditions and protocols might be. And from time to time we would go and do audits, operational reviews, spot checks, file reviews if we think that's appropriate. Contrast that with something that would be considerably less regulated [where] we are not prescriptive... We are only concerned to make sure that [people] are protected and that their services are accessible. (007)

Not all performance measures are dictated through coercive pressures. In some cases the government is interested in creating norms of practice in partnership with the voluntary sector.

...we've had to work pretty hard[with them] at figuring out, at a big pre-program level, getting good meaningful performance measures that are going to tell taxpayers that we are paying for that program so what is it doing. (009)

Others, in different ministries, think that creating performance measures is best left to the agencies to work out for themselves. For example:

The real answer in my mind is to allow some of these sectors to develop standards of their own and to be accountable for their own adherence to the standards they set. (010)

There is some controversy as to just how much control the government should be exerting. Some respondents think that it is necessary for government to keep closer tabs, especially in light of new "governance-in-accountability" framework.

We certainly tightened up the requirements of an organization. And that's certainly created some concern, no question about it, but our feeling is that if we're going to be giving government dollars then we want to ensure that they're spent efficiently and effectively. (003)

Others fear that the government is trying to exert too much control. They point to an interesting paradox. As government demands more accountability from the organizations, they themselves are attracting more responsibility for what happens. Clearly these respondents would favour more informal coercion that maintains a more loosely-coupled relationship (Weick, 1976; Fusarelli, 2002).

I think it is to the government's serious disadvantage to try [to exert more control], because as soon as they start exerting more control you take more ownership, the more ownership you take, the more accountable you are for anything that goes wrong. And it's to the government's advantage to make sure that there is a lot more distance between them and the groups. (005)

...what's become increasingly evident though is that as .... government sets more standards, policies, and monitors more closely, in direct proportionality, it attracts political accountability back on its own. So we are in a very interesting cycle right now where government, even though we are buying services from socalled third parties, in fact attracts all the political accountability. (010)

Still other respondents worry that accountability requirements are too onerous for smaller organizations receiving relatively small amounts of money. 
We ask for a lot of information, sometimes for a small amount of money....If there was something I would like to see it might be something wonderful to see government-wide projects to try and reduce some of these reporting requirements. (004)

Clearly there is an attempt in government ministries, in accordance with their own new procedures, to tighten accountability standards for the agencies in their purview. Indeed, in previous surveys, increased accountability was the most frequently cited change in operations that nonprofit organizations mentioned (Meinhard \& Foster, 2003). What is interesting in the present interviews is the vacillation among civil servants with respect to the way in which to create new standards of performance: a) by government edict, b) by a process of government-agency consultation, or c) by sector self-regulation. These may be seen as corresponding to a) formal and b) informal coercive pressures, and c) normative pressures, respectively. This finding supports the contention that it is often difficult to tease out the exact source of institutional isomorphism (Dimaggio and Powell, 1983). At times, even in the same ministry, isomorphic pressures may simultaneously take on different forms.

Our interviews revealed another interesting aspect about the process of institutional isomorphism. The way in which policy is formulated and implemented is neither direct, nor unidirectional. The political echelon of government sets the tone for new policy, sometimes as a result of consultation, and sometimes simply as an interpretation of an electoral mandate. There was broad agreement among our respondents that the voluntary sector was not formally consulted with respect to the changes introduced by the Progressive Conservative government from 19951999. Nor were the ministries themselves consulted.

This government does not believe in consultation. This government knows what it wants to do. First of all it had the "Common Sense Revolution," it had consulted with everybody that it needed to consult with [before the elections] and it did the things that the platform said (008)

Despite this, what emerges is a picture of the ministries acting as a broker between their nonprofit stakeholders and their political bosses.

It's my job as an Ontario public servant obviously to represent the government to these groups. And I'm not going to do anything fast or loose that embarrasses the government or whatever but I'm going to be straight forward in explaining ...what the government policy is, how it affects them and carry their message back to decision makers and try to connect the two of them. (006)

Brokering can at times simply be a mellowing of the message. As one respondent explains, some of the new policies may seem harsh on recipients of government aid, so it is the Ministry's role to interpret the new programs in a more palatable way.

I guess the challenge for people like me working in the field is understanding that [we have to do our] level best to make these programs meaningful, notwithstanding lots of the political rhetoric and the appeal to the lowest common denominator in people's worst instincts. So in Ontario, a lot of good work has been done notwithstanding the mean spirited way in which some of these reforms have been sold. There is a huge polarity in the society and...enough said. (010) 
Others concur that it is their responsibility to convey policy and facilitate to help their agencies implement it.

If you have a good relationship, particularly at the ministry level, most of them understand that it is the government of the day that leads policy. They provide the policy and it's our job to implement it. Most organizations understand that... Quite often we're facilitating, whether it's activities in advance, or there may be some problems or issues in particular sector, then we're working with that sector. (003)

So in a way government [i.e. the ministry] is a body that can be there to help understand and mediate in a number of issues and look at things from a bigger policy perspective and understand things in a different prism. (001)

Facilitation often results in bi-directional learning.

The kind of approach that we've taken with the volunteer sector is very much a facilitation approach and dialogue and providing opportunities for dialogue. And taking some of the learning from that in developing programs. But there's always a lot of back and fourth. (004)

Developing and nurturing stakeholder relations not only for service delivery but also for policy development is seen as a healthy trend for the future.

We are starting [to work] horizontally. We interpret that to mean not only working with other ministries but working with stakeholders outside and engaging the stakeholders in the policy development process. They have always been involved in the delivery side of it. And I think involving the customer groups ...early on in the policy process is going to be a continuing very healthy trend of government. I think in the past 10-15 years there has been recognition that the best policy development happens with the people affected by the policies as opposed to ivory towers in government. So I think you'll see that trend continuing - government reaching out to the voluntary sector for policy. (006)

It appears that what eventually results as isomorphic practices in a population of organizations is the result of a process of mediated negotiations between policy setters (political echelon), policy brokers (civil service) and policy implementers (voluntary sector).

\section{Encouragement of Partnerships}

The Ontario Government's emphasis on efficiency and cost cutting has led to encouraging nonprofit organizations to partner with other organizations, both nonprofit and forprofit. Unlike demands for accountability, desirability of partnerships is almost always informally encouraged rather than formally demanded, although it sometimes is a requirement to receive funding.

Partnerships with other nonprofits. Partnering with other nonprofits is seen as a way of reducing redundancies, saving money and improving practice. 
I guess one of the concerns we have is that if you look at virtually any sector there are a lot of nonprofit organizations. And I think you would find an overlap in a lot of areas. But we've been trying to encourage consolidation or sorting out where the overlap is. (003)

I think that collaboration and partnership are going to be critical... I don't think that [the pressure to collaborate is] going to be reduced. (011)

We will say to smaller organizations we won't fund you separately, but you could seek a partnership. (004).

Partnerships with the private sector. The Progressive Conservative government recognized that partnerships between nonprofit organizations and the corporate sector may be an expedient way in which nonprofit organizations can reduce their reliance on government funding. In order to encourage the participation of the corporate sector, they created opportunities for partnerships though an initiative called "Ontario's Promise." The objective is to foster "the development of partnerships that will promote a shared responsibility and citizen involvement in areas impacting on children and youth." It is a non-partisan initiative led by an advisory board that works with all sectors of society, including corporations, non-profit agencies, and the volunteer sector.

[It's] all about trying to get communities and more particularly corporations to commit more corporate resources, to programs for children and youth. And corporate resources can mean money but it can also mean time... So it's kind of like the corporation enabling what the communities used to do on their own. (007)

Aside from "Ontario's Promise", very few other government initiated partnership schemes are mentioned, although some ministries have their own programs of matched funding.

So I think in the last decade, we would see policies that have moved from grants to more strategic [forms of revenue generation]. We'll help leverage support from other players if we can't contribute ourselves. We're pilots of the small projects [in which] we are hoping to leverage more corporate sector support through a matching program. (017)

Still, corporate partnerships are encouraged as a viable way to augment funding.

There is not enough money to look after our vulnerable population, so let's go to the businesses. (013)

We encourage them to expand their revenue basis. Many of them[voluntary organizations] are very successful at doing it. (009)

It seems that the main driving force for partnerships, both within the third sector and with the corporate sector, is the quest of greater efficiencies and revenue diversification. However, our respondents identified other benefits as well.

I think we should be looking at a model where the three of us are at the same table. And I've seen some good examples of that, where nonprofit sectors work with government and private sector, certainly in a lot of the[...] activities that 
we're involved in... There was a good example where a lot of nonprofit organizations and volunteers got involved. Business sector was there for sponsorship and we were there.... We were at the table with our team of experts, organizing [activities] for quite a number of years. And we had the nonprofit sector involved in organizing other activities there. So as I said before, I see it as an equal partnership. (003)

We in the ministry have seen the business sector as a really important partner when we have been dealing, for example, with helping voluntary sector use IT more effectively. Business has been a very important partner. (004)

We have agreements [that] are definitely partnerships. They are partnerships between the ministry, industry, and [nonprofit] groups. (005)

From the surveys mentioned above, as well as from numerous other studies (e.g. Drumwright, Cunningham and Berger, 2000), it is clear that there is a growing trend to form partnerships, particularly with for-profit entities. This can be only partly attributed to government encouragement, and in some cases, even requirement of partnering with other organizations. Mimetic forces must also be at play, as it becomes more fashionable for for-profit organizations to show their corporate citizenship. Indeed, there may even be normative pressures on corporations to partner with charities, as more and more consumers are expecting organizations to display social responsibility.

\section{Conclusions}

Voluntary organizations dependent on provincial funding have undergone significant changes in their relationship with government. The implications of these changes have been recorded in several studies that attest to widespread adoption of stricter accountability measures, and greater engagement in collaborative relations and partnerships (Meinhard \& Foster, 2003; Rice and Prince, 2000). In organizational literature, such widespread trends within a population of organizations are commonly interpreted as evidence of isomorphism. Conjectures are made, based on observations from the environment, as to what type of pressures, competitive or institutional (Oliver, 1988; Chuang, Hennessey \& Thompson, 2000), coercive, mimetic or normative (Mizruchi \& Fein, 1999) are responsible for the observed isomorphism. Very few studies actually look at the process of isomorphism (Mizruchi \& Fein, 1999).

Without examining processes, the complexities of institutional isomorphism can be overlooked. For example, in this study, we could simply infer from observed changes in government accountability requirements, that the increase in organizational accountability is a result of coercive isomorphism. However, as this study shows, when examining the actual processes, the story is neither so simple nor so clear-cut.

Certainly, increased accountability in the Ontario voluntary sector is a result of coercive institutional pressures. However, the coercive pressures are not as formal as one would imagine. The interviews reveal that many accountability requirements are quite informal. Some protocols for accountability are worked out in discussions between ministry officials and voluntary organizations. In other cases it is left to the organizations to decide how to measure, report and implement. There are suggestions that sector wide protocols be established by organizations themselves, which would lead to normative isomorphism. This is preferred by some civil servants who fear that the trend to government dictated accountability requirements may lead to tight 
coupling that will restrict organizational independence and will confer ultimate accountability to the government.

Although impossible to discern in this study, mimetic isomorphism may also play a role, as organizations adopt protocols used in other organizations. Examining processes in this way reinforces Dimaggio's and Powell's (1983) contention that it is very difficult to empirically separate the forces of isomorphism. In this study we can attest to the fact that at least both formal and informal coercive isomorphism is currently contributing to the observed widespread increase in organizational accountability.

The interviews also reveal that coercive isomorphism may be mediated by informal negotiations. Although policies may be formulated without consultation by the political echelon, they are often reinterpreted and softened by civil servants who are more aware of the capabilities and limitations of their voluntary sector constituents. There is even controversy as to whether small organizations should be held to stringent reporting requirements. It seems that as long as informal pressures work, there is a reluctance to use more formal protocols. However, as Covaleski and Dirsmith (1988) demonstrate, governments can ultimately reject negotiated suggestions and enforce compliance to institutional demands.

Policy with respect to partnerships is less clear. There is very little evidence of formal coercion, although it does exist. It is our contention that there must be strong mimetic pressures operating, perhaps stronger than the informal institutional coercion that we have observed.

It was clear from the interviews that different ministries have different relations with their voluntary sector constituents. Unfortunately we were unable to link accountability practices with the ministries to which the voluntary organizations report. Future research might compare the different practices in accountability reporting according to different ministry requirements. This would be a good test of coercive isomorphism: homogeneity within ministerial jurisdictions and diversity between ministerial jurisdictions.

The major weakness of this analysis is that the study was not designed to investigate isomorphism. Rather, it became clear from the analysis of the interviews and our knowledge of what was taking place in the voluntary sector with respect to accountability and partnering, that what we were observing was a complex process of isomorphic change in the sector. For this study, we did not measure the changes in accountability practices in the sector; we relied exclusively on secondary reports from other surveys. This weakness notwithstanding, the findings of this study are instructive. They point to a complex process of isomorphism in times of change that depends on active agency, negotiation and brokering.

\section{References}

Covaleski, M.A. and Dirsmith, M.W., "An Institutional Perspective on The Rise, Social Transformation, And Fall Of A University Budget Category," Administrative Science Quarterly, 33 (1988), 562-587.

Chuang,Y., Hennessey, D.A. and Thompson, K., "Diversity And Similarity Of Organizational Form In New York City Newspapers 1801-1988," presented at the annual meeting of Academy of Management 2000, Toronto. 
DiMaggio, P.J., and Powell, W.W., "The Iron Cage Revisited: Institutional Isomorphism And Collective Rationality In Organizational Fields," American Sociological Review, 48 (1983), 147160.

Drumwright, M., Cunningham, P. and Berger, I., "Social Alliances: Company/nonprofit collaboration," Cambridge, MA: Marketing Science Institute Working Paper \# 00-101, 2000.

Fusarelli, L.D., "Tightly Coupled Policy In Loosely Coupled Systems: Institutional Capacity And Organizational Change," Journal of Educational Administration, 40 (2002), 561-575.

Hannan, M.T. and Freeman, J., "The Population Ecology of Organizations," American Sociological Review, 82 (1977), 929-964.

Hawley, A., "Human Ecology." In David L Sills (Ed.), International Encyclopaedia of the Social Sciences. New York: Macmillan, 1968, 328-337

Holstein, J.A. and Gubrium, J.F., The Active Interview, Thousand Oaks, CA: Sage, 1995.

Johnson, A., "Social Policy In Canada: The Past As It Conditions The Present," In Seward, S.B. (Ed). The Future of Social Welfare Systems in Canada and the United Kingdom, Halifax:

Institute for Research on Public Policy, 1987.

Meinhard, A. and Foster M., "Differences In The Response Of Women's Voluntary Organizations To Shifts In Canadian Public Policy," Nonprofit and Voluntary Sector Quarterly, 32 (2003), 366-396.

Meyer, J.W., and Rowan, B., "Institutionalized Organizations: Formal Structure As Myth And Ceremony," American Journal of Sociology, 83 (1977), 340-363.

Mizruchi, M.S. and Fein, L.C. "The Social Construction Of Organizational Knowledge: A Study Of The Uses Of Coercive, Mimetic, And Normative Isomorphism." Administrative Science Quarterly, 44 (1999), 653-684.

Oliver, C., "The Collective Strategy Framework: An Application To Competing Predictions Of Isomorphism," Administrative Science Quarterly, 33 (1988), 543-561.

Rice, J. J. and Prince, M. J., Changing Politics of Canadian Social Policy, Toronto: University of Toronto Press, 2000.

Richmond, T. and Shields, J., Third Sector Restructuring and the New Contracting Regime: The Case of Immigrant Serving Agencies in Ontario, Centre for Voluntary Sector Studies, Ryerson University, Working Paper Series, No. 25, 2003.

Scott, J. T., Voluntary Sector In Crisis: Canada's Changing Public Philosophy Of The State And Its Impact On Voluntary Charitable Organizations, Ann Arbor: University Microfilms, 1992.

Siegel, P.H. and Rigsby, J.T., "Institutionalization And Structuring of Certified Public Accountants: An Analysis of The Development Of Education And Experience Requirements For Certified Public Accountants," Journal of Management History, 4 (1998), 81-100. 
Smardon, B., "The Federal Welfare State And The Politics Of Retrenchment In Canada,"

Journal of Canadian Studies, 26 (1991), 122-141. Reprinted in Blake, R. and Keshen, J. (Eds.)

Social Welfare Policy in Canada: Historical Readings, Toronto: Copp Clark Ltd. 1995.

Tester, F.J., "One Piece At A Time: Pragmatic Politics And The Demise Of Canadian

Welfarism," in Tester, F.J., McNiven, C. and Case, R. (Eds.) Critical Choices, Turbulent Times, Vancouver: UBC, 1996.

Tucker, D.J., Singh, J.V. and Meinhard, A.G., "Organizational Form, Population Dynamics And Institutional Change: A Study Of Birth Patterns Of Voluntary Organizations," Academy of Management Journal, 33 (1990), 151-178.

Weick, K.E., Educational Organizations as Loosely Coupled Systems, Administrative Science Quarterly, 21 (1976), 1-19 